\title{
Thermodynamic Modeling of Chiral Compounds Solubility Using Correlative and Predictive Models
}

\author{
Morteza Salimi ${ }^{1, *}$, Bahman Zarenezhad ${ }^{1}$, Hossein Fakhraian $^{2}$ and Ebrahim Choobdari ${ }^{3}$ \\ ${ }^{1}$ Faculty of Chemical, Gas and Petroleum Engineering, Semnan University, Semnan, Iran \\ ${ }^{2}$ Department of Chemistry, Imam Hossein University, Tehran, Iran \\ ${ }^{3}$ Department of Chemistry, Shahid Beheshti University, Evin, Tehran, Iran
}

\begin{abstract}
Many intermolecular forces and parameters affect the solubility of a compound in a solvent. Various thermodynamic models are presented to predict these parameters and determine solid liquid equilibrium data. By selecting suitable thermodynamic model for solubility modeling, calculation error is reduced and the results will be closer to the experimental data. Herein, the ability of two predictive and two correlative models in solubility modeling of chiral compounds is investigated. Thus, solubility of pure and racemic forms of chiral Ketamine, Mandelic acid and 3Chloromandelic acid is evaluated using UNIQUAC and NRTL models. The solubility modeling of pure and racemic forms of Ketamine in Ethanol is also determined by UNIFAC and NRTL-SAC models. There are good agreement between experimental data and results of NRTL and UNIQUAC models. Predictive NRTL-SAC model shows smaller deviation than UNIFAC in solubility determination of pure and racemic form of Ketamine.
\end{abstract}

Keywords: Solubility, Chiral compounds, Thermodynamic modeling, NRTL-SAC, UNIFAC, UNIQUAC, NRTL.

\section{INTRODUCTION}

Molecules with the same structure and shape in the presence of asymmetric carbon atoms can be found in two forms that are called enantiomers. This feature is observed in large group of molecules that form chiral compounds [1,2]. Despite these molecules have same structure and physical properties; they cause different pharmacological effects in biological systems [3, 4]. For this reason separation and purification of these molecules, especially in food and pharmaceutical industry is very important. Crystallization is an economical way for separation and purification of these compounds [5]. Precise knowledge about solid liquid equilibrium and phase diagram of a system is required for design and modeling of separation process [6]. Experimental determination of phase behavior and solubility is a tedious and time consuming task. Many thermodynamic models have been developed to determine solubility of different compounds. There are many published works using popular correlative activity coefficient models such as Wilson [7], NRTL [8], and the UNIQUAC [9], for solubility determination of compounds. In some cases there is necessary to determine appropriate solvent for chemical synthesis or determine solubility with least amount of experimental results. Use of predictive models such as Hansen [10], group contribution UNIFAC [11] and segment contribution NRTL-SAC [12] models can be good

*Address correspondence to this author at the Faculty of Chemical, Gas and Petroleum Engineering, Semnan University, Semnan, Iran; Tel/Fax: +982333383926; E-mail: morteza_salimi86@yahoo.com choice in these cases. In this work, we consider both predictive and correlative models for solubility prediction. Solubility of pure and racemic forms of Ketamine is determined by NRTL and UNIQUAC models. One of the recent works have been published on solubility and phase diagram modeling of tautomeric forms of Ranitidine hydrochloride by UNIQUAC model [13]. In other similar works solubility of Stearic acid, Ranitidine hydrochloride, and Stavudine have been well determined in some organic solvents using NRTL and UNIQUAC models [14]. The experimental solubility data of six structurally related Phenothiazines were also determined by Wilson, NRTL and UNIQUAC models [15]. The solubility of two polymorphs of Buspirone hydrochloride in Isopropanol, Water and mixture of these two solvents have been determined by Rohani et al. The UNIQUAC and UNIFAC model gave good prediction capability in solubility determination of these compounds [16]. Solubility of three Arylamine molecules in Methanol, Hexane, and Benzene have been investigated by UNIQUAC and UNIFAC models [17]. In other work the results of NRTL-SAC and UNIFAC equations in solubility determination of six cases of solvents were studies and compared. For systems of heavy alcohols, NRTL-SAC gave better prediction than UNIFAC and in binary systems under study, UNIFAC model was better than NRTL-SAC [18]. In this study, we examined and compared the solubility of pure and racemic forms of Ketamine, Mandelic acid and 3-Chloromandelic acid using UNIQUAC and NRTL models, as well the solubility of pure and racemic form of Ketamine, determined by NRTL-SAC and UNIFAC 

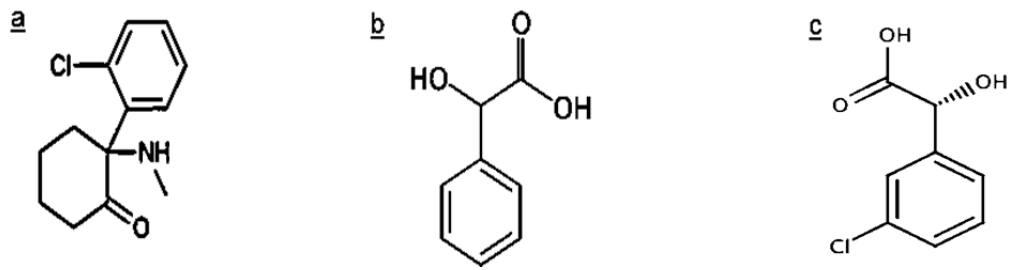

Figure 1: Molecular structure of a: Ketamine, b: Mandelic acid c: 3-Chloromandelic acid.

models. Figure 1 shows the structure of the three mentioned compounds.

\section{THEORETICAL BACKGROUND}

\section{A. Solubility}

Solubility is calculated by the following equation [19]:

$\ln \frac{f_{2}^{L}}{f_{2}^{S}}=\frac{\Delta H_{m e l}}{R T_{t p}}\left(\frac{T_{t p}}{T}-1\right)-\frac{\Delta C_{P}}{R}\left(\frac{T_{t p}}{T}-1\right)+\frac{\Delta c_{p}}{R} \ln \frac{T_{t p}}{T}$

Where, $\Delta H_{m e l}$ and $T_{t p}$ are the melting enthalpy and temperature, $\mathrm{R}$ is the universal constant, $\Delta C_{P}$ is heat capacity difference between solid and liquid form of solute and the ratio of $\frac{f_{2}^{L}}{f_{2}^{S}}$ is calculated by following equation:

$x_{2} \gamma_{2}=\frac{f_{2}^{L}}{f_{2}^{S}}$

Where, $\gamma_{2}$ is the activity coefficient and $x_{2}$ is the mole fraction of solute in solvent.

\section{B. NRTL Model}

Activity coefficient in NRTL model and for binary systems is calculated from equation 3 .

$$
\begin{aligned}
& \ln \gamma_{2}=x_{1}^{2}\left[\tau_{12}\left(\frac{G_{12}}{x_{2}+x_{1} G_{12}}\right)^{2}+\frac{\tau_{21} G_{21}}{\left(x_{1}+x_{2} G_{21}\right)^{2}}\right] \\
& G_{12}=\exp \left(-\alpha_{12} \tau_{12}\right) \quad G_{21}=\exp \left(-\alpha_{12} \tau_{21}\right)
\end{aligned}
$$

In the above equations, $\tau_{12}$ and $\tau_{21}$ are the dimensionless interaction parameters, related to the interaction energy parameters, $\left(g_{12}-g_{22}\right)$ and $\left(g_{21}-g_{11}\right)$ by following equations:

$\tau_{12}=\frac{g_{12}-g_{22}}{R T} \quad \tau_{21}=\frac{g_{21}-g_{11}}{R T}$

$\left(g_{12}-g_{22}\right)$ and $\left(g_{21}-g_{11}\right)$ are NRTL adjustable parameters with $(\mathrm{J} / \mathrm{mol})$ unit, and $\alpha_{12}$ is NRTL dimensionless parameter determined by regression of experimental equilibrium data.

\section{UNIQUAC Model}

For binary system in UNIQUAC equation activity coefficient is calculated by:

$$
\begin{aligned}
& \ln \gamma_{2}=\ln \frac{\Phi_{2}}{x_{2}}+\frac{z}{2} q_{2} \ln \frac{\theta_{2}}{\Phi_{2}}+\Phi_{1}\left(l_{2}-\frac{r_{2}}{r_{1}} l_{1}\right)- \\
& q_{2}^{\prime} \ln \left(\theta_{2}^{\prime}+\theta_{1}^{\prime} \tau_{12}\right)+\theta_{1}^{\prime} q_{2}^{\prime}\left(\frac{\tau_{12}}{\theta_{2}^{\prime}+\theta_{1}^{\prime} \tau_{12}}-\frac{\tau_{12}}{\theta_{1}^{\prime}+\theta_{2}^{\prime} \tau_{21}}\right) \\
& \Phi_{i}=\frac{r_{i} x_{i}}{r_{1} x_{1}+r_{2} x_{2}} \\
& \theta_{2}=\frac{q_{2} x_{2}}{q_{1} x_{1}+q_{2} x_{2}} \quad \theta_{2}^{\prime}=\frac{q_{2}^{\prime} x_{2}}{q_{1}^{\prime} x_{1}+q_{2}^{\prime} x_{2}} \\
& \tau_{12}=\exp \left(-\frac{a_{12}}{T}\right) \quad \tau_{21}=\exp \left(-\frac{a_{21}}{T}\right) \\
& l_{1}=\frac{z}{2}\left(r_{1}-q_{1}\right)-\left(r_{1}-1\right) \quad l_{2}=\frac{z}{2}\left(r_{2}-q_{2}\right)-\left(r_{2}-1\right)
\end{aligned}
$$

In the above equations, $a_{12}$ and $a_{21}$ are UNIQUAC adjustable parameters, the coordination number $z$ is set equal to 10. $r, q$ and $q^{\prime}$ are constants of pure components depending on the molecular size and external surface area. Parameters $r_{i}$ and $q_{i}$ are calculated as the summation of parameters $R_{k}$ and $Q_{k}$ (equation 11) which are group volume and surface area parameters given by Hansen et al. [24].

$q_{i}=\sum_{k} v_{k i} Q_{k} \quad r_{i}=\sum_{k} v_{k i} R_{k}$

$v_{k i}$ : the number of groups of type $\mathrm{k}$ in molecule $\mathrm{i}$.

\section{NRTL-SAC Model}

According to NRTL-SAC model each molecule can have one to four conceptual segments. Hydrophilic $(Z)$ segment presents molecular surface with tendency to form hydrogen bond, hydrophobic (X) segment doesn't form Hydrogen bond, polar attractive $\left(Y^{+}\right)$and polar repulsive $\left(Y^{-}\right)$simulate electron donor and acceptor of 
polar molecules. Activity coefficient in NRTL-SAC model is the sum of combinatorial and residual parts:

$\ln \gamma_{I}=\ln \gamma_{I}^{C}+\ln \gamma_{I}^{R}$

Residual part calculated by following equation:

$\ln \gamma_{I}^{R}=\ln \gamma_{I}^{l c}=\sum_{m} r_{m, I}\left[\ln \Gamma_{m}^{l c}-\ln \Gamma_{m}^{l c, I}\right]$

Where $\ln \Gamma_{m}^{l c}$ and $\ln \Gamma_{m}^{l c, I}$ are activity coefficients of segment species $\mathrm{m}$ in solution and component I respectively.

$\ln \Gamma_{m}^{c c}=\frac{\sum_{J} x_{j} G_{j m} \tau_{j m}}{\sum_{k} x_{k} G_{k m}}+\sum_{m^{\prime}} \frac{x_{m^{\prime}} G_{m m^{\prime}}}{\sum_{k} x_{k} G_{k m^{\prime}}}\left(\tau_{m m^{\prime}}-\frac{\sum_{J} x_{j} G_{j m^{\prime}} \tau_{j m^{\prime}}}{\sum_{k} x_{k} G_{k m^{\prime}}}\right)$

$\ln \Gamma_{m}^{l c, I}=\frac{\sum_{J} x_{j, I} G_{j m} \tau_{j m}}{\sum_{k} x_{k, l} G_{k m}}+\sum_{m^{\prime}} \frac{x_{m, I} G_{m m^{\prime}}}{\sum_{k} x_{k, l} G_{k m^{\prime}}}\left(\tau_{m m^{\prime}}-\frac{\sum_{J} x_{j, I} G_{j m^{\prime}} \tau_{j m^{\prime}}}{\sum_{k} x_{k, l} G_{k m^{\prime}}}\right)$

$x_{j}=\frac{\sum_{J} x_{J} r_{j, J}}{\sum_{J} \sum_{i} x_{I} r_{i, I}}$

$x_{j, I}=\frac{r_{j, J}}{\sum_{i} r_{i, I}}$

In above equations $i, j, k, m$ and $m^{\prime}$ are segment based indices, $I$ and $J$ are component indices, $x_{j}$ and $x_{j, I}$ are the segment based mole fractions. $G_{i, j}$ and $\tau_{i, j}$ are the local binary parameters related to each other by following equation:

$G_{i j}=\exp \left(-\alpha_{i j} \tau_{i j}\right)$

For combinatorial part we have:

$\ln \gamma_{i}^{C}=\ln \frac{\phi_{i}}{x_{i}}+1-r_{i} \sum_{J} \frac{\phi_{J}}{r_{J}}$

$r_{I}=\sum_{I} r_{i, I}$

$\phi_{I}=\frac{r_{I} x_{I}}{\sum_{J} r_{J} x_{J}}$

$r_{I}$ and $\Phi_{I}$ are total segment number and segment mole fraction in the mixture.

\section{E. UNIFAC Model}

Total activity of a component in UNIFAC model is sum of combinatorial and residual parts as equation 12 .
Combinatorial part for component $i$ is founded from the following equation:

$$
\ln \gamma_{i}^{c}=\ln \frac{\varphi_{i}}{x_{i}}+\frac{z}{2} \ln \frac{\theta_{i}}{\varphi_{i}}+l_{i}-\frac{\varphi_{i}}{x_{i}} \sum_{i} x_{j} l_{j}
$$

Where:

$$
z=10 \quad l_{i}=\frac{z}{2}\left(r_{i}-q_{i}\right)-\left(r_{i}-1\right)
$$

$l_{j}$ is a compound parameter and $\mathrm{z}$ is coordination number equal to 10. $\theta_{i}$ and $\varphi_{i}$ are the area fraction and segment fraction of component i respectively and are related to mole fraction of species $i$ in the mixture:

$$
\theta_{i}=\frac{x_{i} q_{i}}{\sum_{j} x_{j} q_{j}} \quad \varphi_{i}=\frac{x_{i} r_{i}}{\sum_{j} x_{j} r_{j}}
$$

$r_{i}$ and $q_{i}$ are the pure component surface area and volumes and are calculated by Van der Waals group volume and surface area (equation 11).

The residual part of the activity coefficient of UNIFAC equation is calculated as follow:

$\ln \gamma_{i}^{R}=\sum v_{k i} Q_{k}\left(\ln \Gamma_{k}-\ln \Gamma_{k}^{(i)}\right)$

Where $\Gamma_{k}$ and $\ln \Gamma_{k}^{(i)}$ are respectively group residual activity coefficient and residual activity coefficient of group $\mathrm{k}$ in a reference solution containing only molecules of type i. Following formula is used for calculation of both $\Gamma_{k}$ and $\ln \Gamma_{k}^{(i)}$.

$\ln \Gamma_{k}=1-\ln \left(\sum_{m} \Theta_{m} \Psi_{m k}\right)-\sum_{m}\left(\frac{\Theta_{m} \Psi_{m k}}{\sum_{n} \Theta_{n} \Psi_{n m}}\right)$

Where $\Theta_{m}$ is summation of area function of group $\mathrm{m}$.

$\Theta_{m}=\frac{Q_{m} X_{m}}{\sum Q_{n} X_{n}}$

$X_{n}$ is the mole fraction of subgroup $\mathrm{m}$ in the mixture. $\Psi_{m n}$ is the group interaction parameter and $U_{m n}$ is energy of interaction between groups $m$ and $n$.

$\Psi_{m n}=\exp \left(-\frac{U_{m n}-U_{n n}}{R T}\right)=\exp \left(-\frac{a_{m n}}{T}\right)$

Where $a_{m n}$ is net energy of interaction between group $m$ and $n$. This interaction energy value is obtained from large sets of equilibrium data which are tabulated for many subgroups [24]. 


\section{RESULTS AND DISCUSSIONS}

Experimental solubility data of pure and racemic form of Ketamine is previously reported [20]. Ternary phase diagram of Ketamine has two eutectic points and shows racemic compound system behavior. Table 1 shows the solubility of pure and racemic forms of this compound in Ethanol at temperature ranges between 25 to 40 degrees centigrade. The binary and ternary phase diagram of 3-Chloromandelic acid have shown racemic behavior for this compound [21]. Solubility data of this compound are presented in Table 2. As well, Table 3 shows experimental solubility data of Mandelic acid [22]. In correlative models ICA optimization algorithm [23] is used to determine adjustable parameters. The objective function is used to minimize the difference of activity coefficients represented in equation 29.

Table 1: Solubility, $S$ (gr Solute $/ 100 \mathrm{gr}$ Solvent), of Ketamine in Ethanol [20]

\begin{tabular}{|c|c|c|}
\hline $\mathbf{T}\left({ }^{\circ} \mathbf{C}\right)$ & $S_{(R S)}$ & $S_{(R)}$ \\
\hline \hline 25.0 & 13.9 & 9.7 \\
\hline 27.5 & 15.1 & 10.4 \\
\hline 30.0 & 16.3 & 11.0 \\
\hline 32.5 & 17.6 & 11.7 \\
\hline 35.0 & 19.0 & 12.4 \\
\hline 37.5 & 20.5 & 13.1 \\
\hline 40.0 & 22.2 & 13.9 \\
\hline
\end{tabular}

Table 2: Solubility, $S$ (gr solute /100 gr solvent), of 3CIMA [21]

\begin{tabular}{|c|c|c|}
\hline $\mathbf{T}\left({ }^{\circ} \mathbf{C}\right)$ & $S_{(R S)}$ & $S_{(R)}$ \\
\hline 15 & 1.7 & 3.3 \\
\hline 20 & 2.1 & 4.1 \\
\hline 25 & 2.6 & 5.0 \\
\hline 30 & 3.1 & 7.0 \\
\hline 35 & 4.1 & 25.6 \\
\hline
\end{tabular}

Table 3: Solubility, $S$ (gr solute $/ 100$ gr solvent), of Mandelic acid in Water [22]

\begin{tabular}{|c|c|c|}
\hline $\mathrm{T}\left({ }^{\circ} \mathrm{C}\right)$ & $S_{(R S)}$ & $S_{(R)}$ \\
\hline \hline 5 & 8.8 & 5.7 \\
\hline \hline 10 & 10.3 & 6.7 \\
\hline 15 & 12.0 & 8.0 \\
\hline 20 & 15.3 & 9.2 \\
\hline 25 & 20.8 & 11.0 \\
\hline 30 & 33.0 & 13.5 \\
\hline
\end{tabular}

$\min f=\sum_{n=1}^{m}\left(\gamma_{\exp }-\gamma_{c a l}\right)^{2}$

Where $\mathrm{m}$ is the number of experiments, $\gamma_{\text {exp }}$ is the experimental activity coefficient and $\gamma_{\text {cal }}$ are activity coefficient determined by thermodynamic models. In NRTL-SAC model, experimental solubility data has been used to determine molecular parameters of compound by MATLAB Isqnonlin function.

To assess the accuracy of the results average relative deviation error are calculated as follow:

$\% A R D=\frac{1}{n}\left(\sum_{i=1}^{n} \frac{\left|S_{\text {exp }}-S_{c a l}\right|}{S_{\exp }}\right) \times 100$

Where $S_{\exp }$ is experimental solubility, $S_{c a l}$ is calculated solubility by thermodynamic models and $n$ is the number of experiments. Table 4 represents experimental enthalpy of fusion and triple point temperature that are used for solubility modeling.

Pure component constants of UNIQUAC equation calculated by group data taken by Hansen et al. [24] are shown in Table 5. Adjustable parameters of UNIQUAC model is determined using this parameters and minimizing equation 29 . The value of adjustable parameters $a_{1}, a_{2}$ for UNIQUAC equation and $\left(g_{12}-g_{22}\right),\left(g_{21}-g_{11}\right)$ for NRTL equation have been determined (Table 6). The average relative deviation error are presented in Table 6. Optimized segment numbers of NRTL-SAC model are shown in Table $\mathbf{8}$. In comparing the results of UNIQUAC and NRTL models in solubility prediction of pure and racemic forms of Ketamine, both models have shown results close to the experimental results, although in both cases, the error of NRTL model is lower.

Figures 2 and $\mathbf{3}$ show experimental and calculated solubility data of pure and racemic form of Ketamine in Ethanol. In the experimental solubility determination of pure 3-CIMA [21], significant solubility increase was observed in temperature ranges above $30^{\circ} \mathrm{C}$. This can be caused from experimental errors. But due to the lack of another report, the modeling has been performed by assuming that this increase of solubility is not a measurement error. This increase is well correlated by UNIQUAC equation and the ARD error for NRTL in temperatures ranges above $30{ }^{\circ} \mathrm{C}$ is relatively high (Figure 4). According to Figure $\mathbf{5}$, solubility modeling of racemic form of 3-CIMA is well correlated in water by both UNIQUAC and NRTL models. Figures 6 and 7 show the results of pure and racemic Mandelic acid solubility modeling with NRTL 
Table 4: Enthalpy of Fusion and Triple Point of Substances

\begin{tabular}{|c|c|c|c|c|c|}
\hline \multirow{2}{*}{} & \multicolumn{2}{|c|}{ Racemate } & \multicolumn{2}{c|}{ Pure substances } \\
\cline { 2 - 6 } & $\Delta H_{\text {fus }}(\mathbf{j} / \mathbf{g r})$ & $T_{t p}\left(C^{\circ}\right)$ & $\Delta H_{\text {fus }}$ (j/gr) & $T_{t p}\left(C^{\circ}\right)$ & 121.0 \\
\hline Ketamine & 120.7 & 92.6 & 120.7 & 117.2 & 20 \\
\hline 3-CIMA & 140.6 & 105.6 & 149.9 & 156.0 & 21 \\
\hline Mandelic acid & 206.0 & 165.0 & 190.0 & \multicolumn{2}{c}{2} \\
\hline
\end{tabular}

Table 5: Pure Component Constants for UNIQUAC Equation

\begin{tabular}{|c|c|c|c|}
\hline & $r$ & $q$ & $q^{\prime}$ \\
\hline \hline Ketamine & 8.768 & 6.608 & 6.608 \\
\hline 3-CIMA & 5.925 & 4.600 & 4.600 \\
\hline Mandelic acid & 5.300 & 4.156 & 4.156 \\
\hline
\end{tabular}

Table 6: Adjustable Parameters for UNIQUAC and NRTL Equation for Pure Enantiomers

\begin{tabular}{|c|c|c|c|c|c|c|c|}
\hline & \multicolumn{3}{|c|}{ UNIQUAC } & \multicolumn{3}{c|}{ NRTL } \\
\cline { 2 - 8 } & $a_{1}$ & $a_{2}$ & \%ARD & $\left(g_{12}-g_{22}\right)$ & $a_{12}$ & $\left(g_{21}-g_{11}\right)$ & \%ARD \\
\hline \hline Ketamine & -133.8 & 3730.0 & 2.7 & 9330.0 & 0.29 & -90000 & 0.3 \\
\hline 3-CIMA & -319.6 & 623.6 & 3.6 & 7769.0 & 0.47 & -43964 & 16.0 \\
\hline Mandelic acid & -289.8 & 487.2 & 0.9 & 31255.6 & 0.32 & -87777 & 0.5 \\
\hline
\end{tabular}

Table 7: Adjustable Parameters for UNIQUAC and NRTL Equation for Racemate

\begin{tabular}{|c|c|c|c|c|c|c|c|}
\hline & \multicolumn{3}{|c|}{ UNIQUAC } & \multicolumn{4}{|c|}{ NRTL } \\
\hline & $a_{1}$ & $a_{2}$ & $\%$ ARD & $\left(g_{12}-g_{22}\right)$ & $a_{12}$ & $\left(g_{21}-g_{11}\right)$ & $\%$ ARD \\
\hline Ketamine & -116.1 & 1996.5 & 1.9 & 8772.5 & 0.44 & -56223.7 & 0.5 \\
\hline 3-CIMA & -57.9 & 90.4 & 1.7 & 9255.9 & 0.46 & -90000.0 & 1.5 \\
\hline Mandelic acid & -337.5 & 634.3 & 3.7 & 20691.0 & 0.44 & -60393.0 & 2.2 \\
\hline
\end{tabular}

Table 8: Optimized Segment Number of Ketamine for NRTL-SAC Model

\begin{tabular}{|c|c|c|c|c|}
\hline & $X$ & $Y^{-}$ & $Y^{+}$ & $Z$ \\
\hline \hline Ketamine & 0.0000 & 0.8375 & 0.5416 & 0.4082 \\
\hline
\end{tabular}

and UNIQUAC models. In both cases, calculated error between experimental and modeling data is lower for NRTL model. In the case of predictive models, due to the lack of NRTL-SAC molecular parameters of Ketamine, these parameters are calculated and presented in Table $\mathbf{8}$. The results of thermodynamic modeling by UNIFAC and NRTL-SAC models for pure and racemic forms of Ketamine are shown in Figures 8 and 9 respectively. The calculation results by UNIFAC model is upperestimated for Ketamine in both pure and racemic forms. Calculation of pure form of Ketamine is underestimated by NRTL-SAC model. NRTL-SAC 


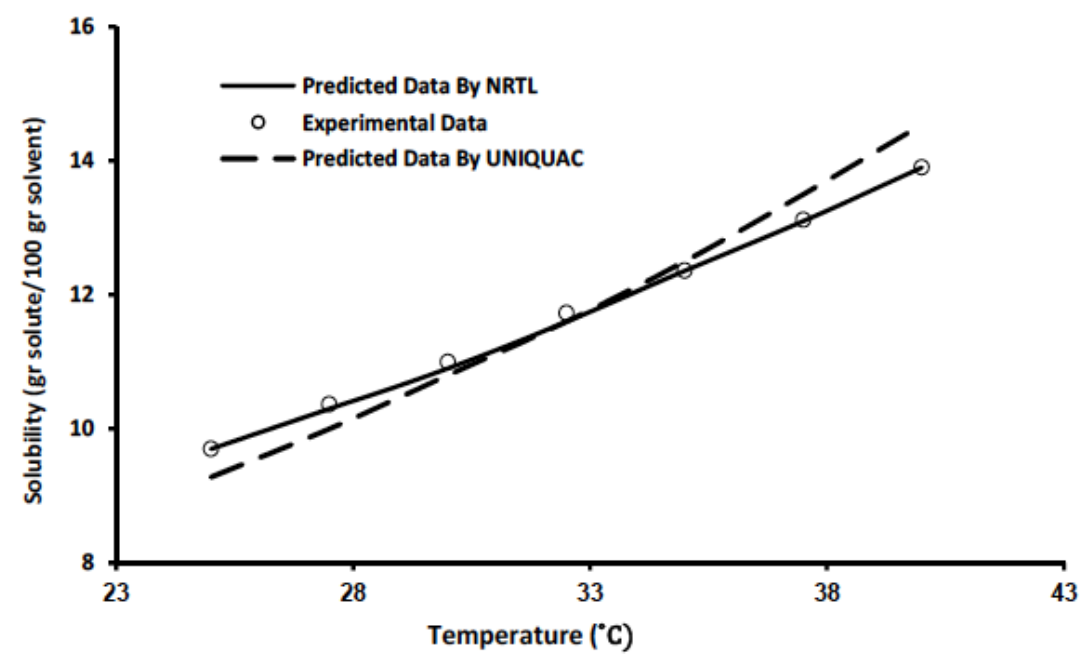

Figure 2: Experimental and predicted solubility determined by correlative models of (R)Ketamine in Ethanol.

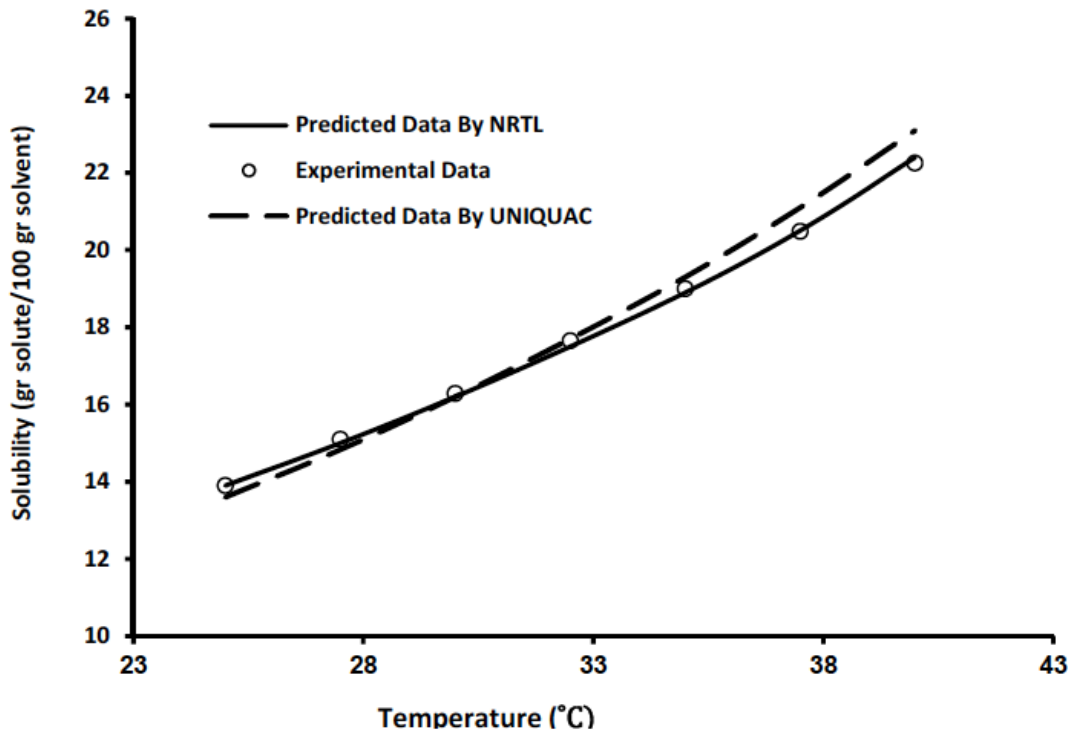

Figure 3: Experimental and predicted solubility determined by correlative models of (RS) Ketamine in Ethanol.

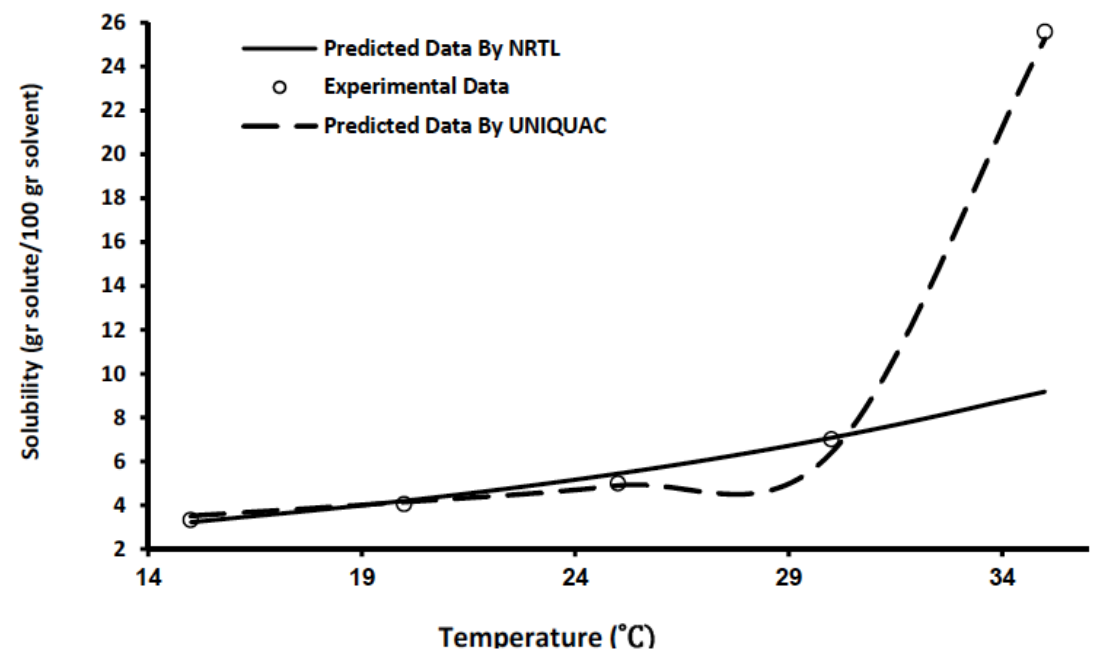

Figure 4: Experimental and predicted solubility determined by correlative models of (R) 3-CIMA in Water. 


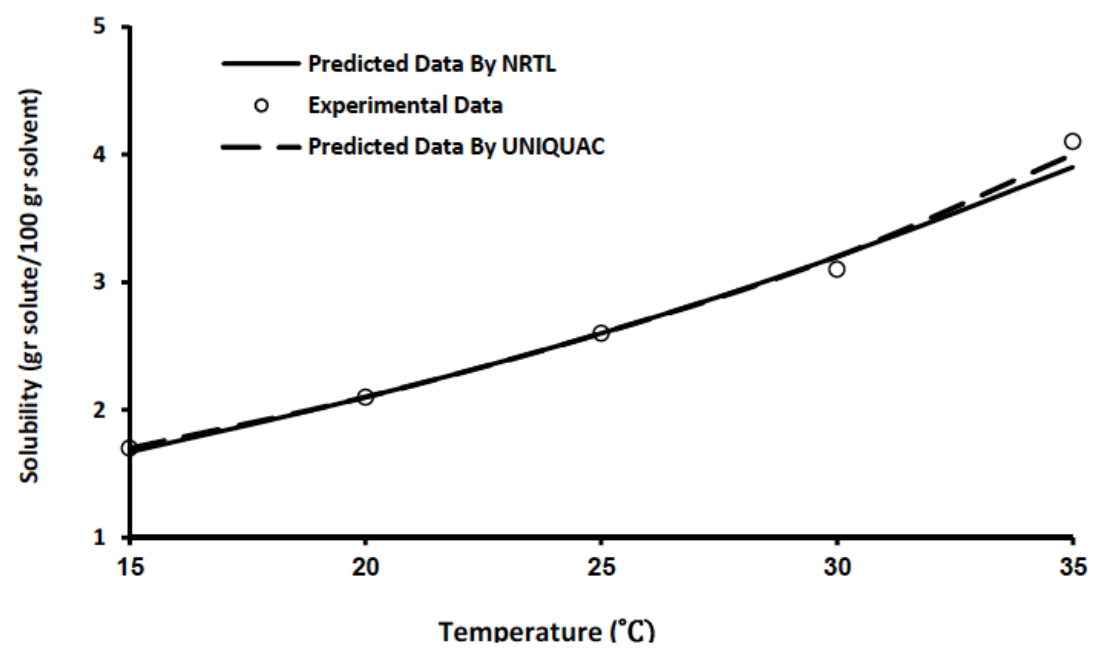

Figure 5: Experimental and predicted solubility determined by correlative models of (RS) 3-CIMA in Water.

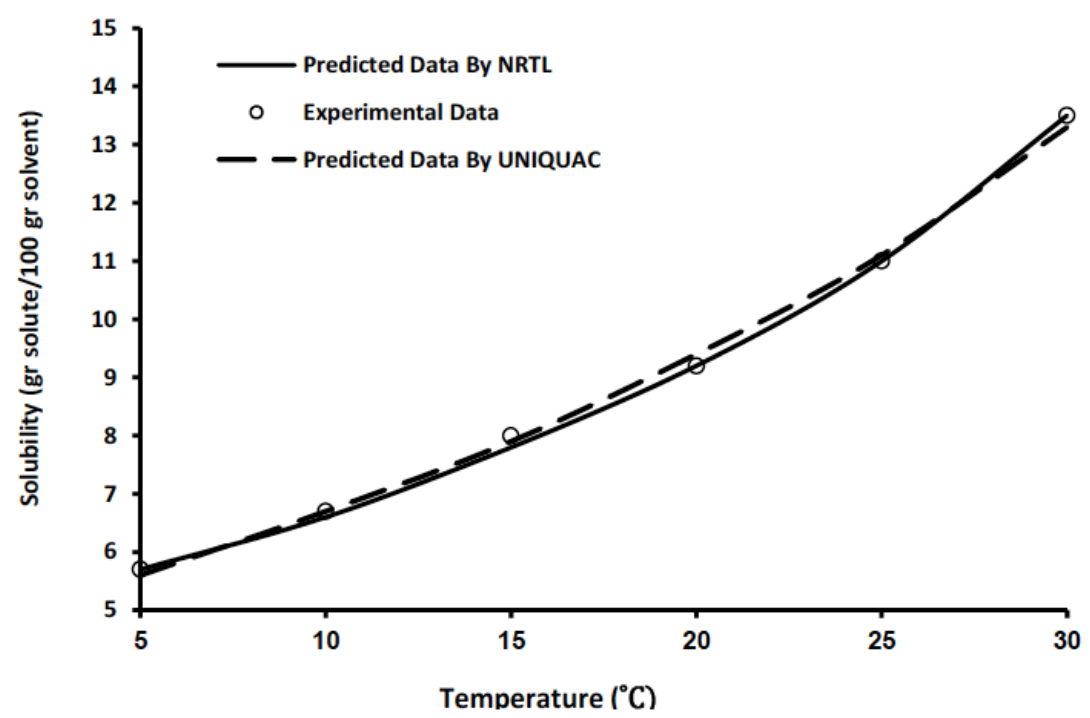

Figure 6: Experimental and predicted solubility determined by correlative models of $(R)$ Mandelic acid in Water.

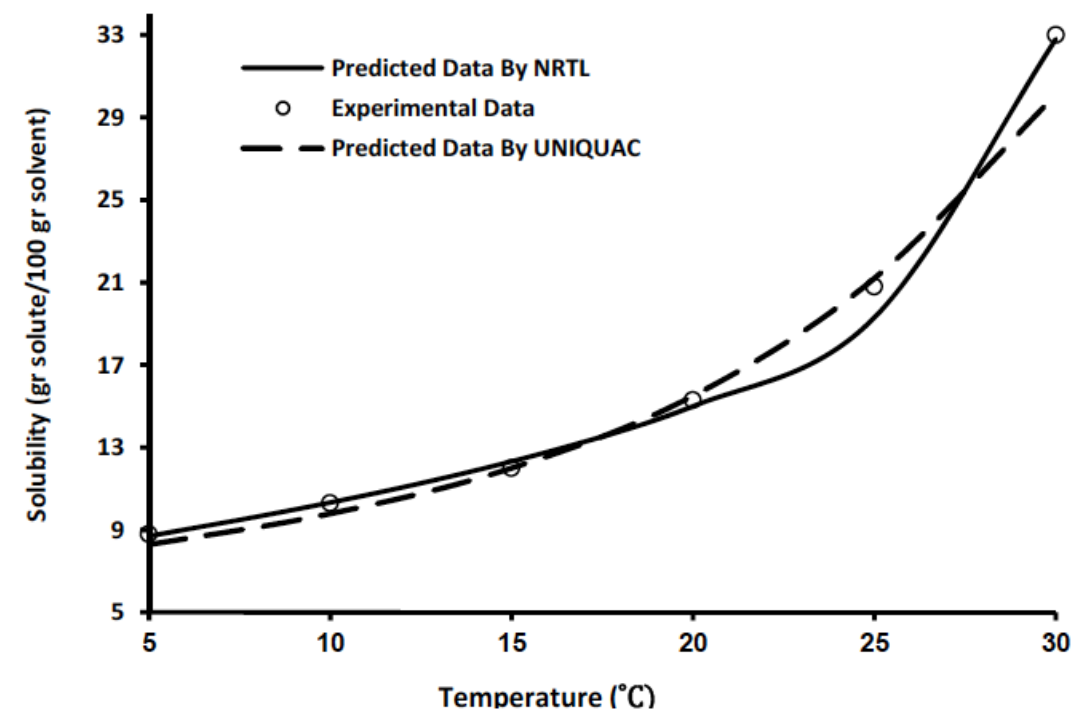

Figure 7: Experimental and predicted solubility determined by correlative models of (RS) Mandelic acid in Water. 


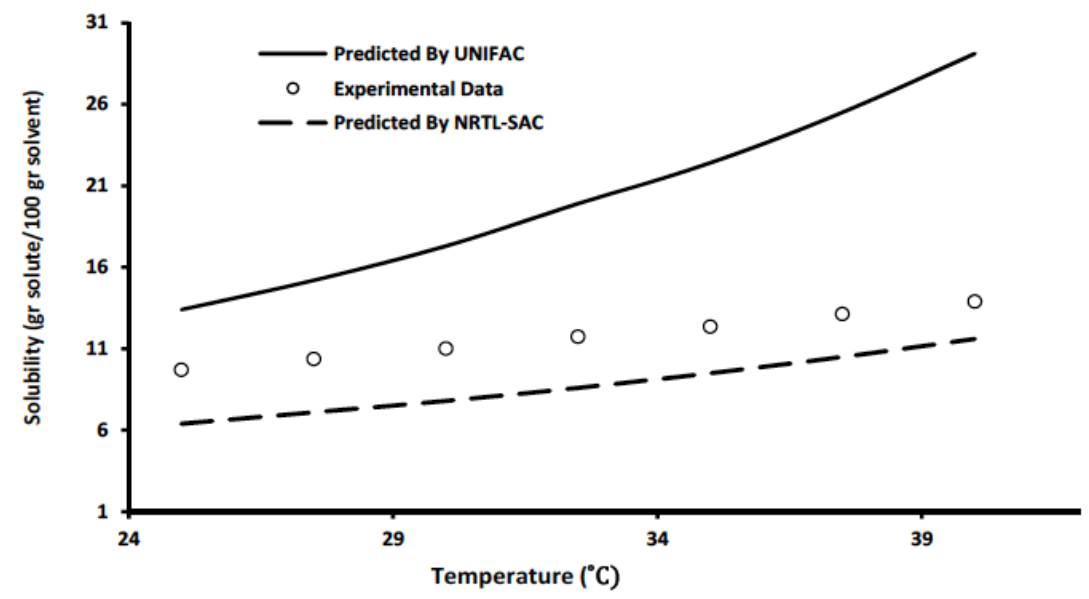

Figure 8: Experimental and predicted solubility determined by predictive models of $(\mathrm{R})$ Ketamine in Ethanol.

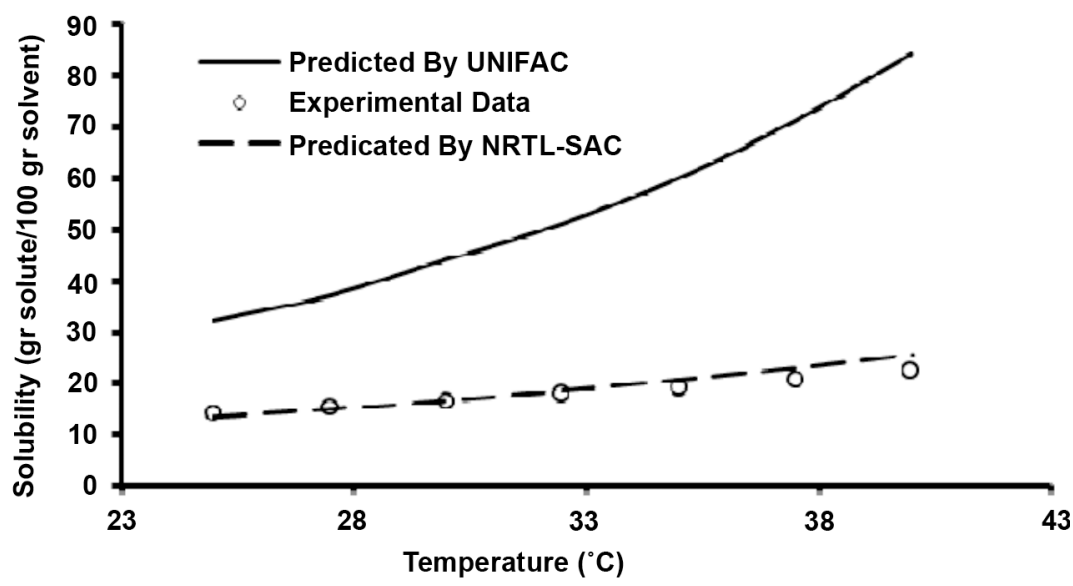

Figure 9: Experimental and predicted solubility determined by predictive models of (RS) Ketamine in Ethanol.

gives good prediction compared to UNIFAC model in solubility modeling of both pure and racemic form of Ketamine.

\section{CONCLUSIONS}

Due to limit entry of thermodynamic models in solubility determination of chiral compounds and widespread application of these models in phase behavior prediction, thermodynamic modeling of pure and racemic forms of Ketamine, Mandelic acid and 3Chloromandelic acid using two correlative and two predictive models are considered. Adjustable parameters for each compound in different models were determined and modeling was completed. In the systems under study, UNIQUAC equation gave good prediction in solubility prediction of pure form of 3CIMA. In other investigated systems, both NRTL and UNIQUAC show small deviation from experimental data although ARD error for NRTL model was lower. In the predictive models NRTL-SAC shows good agreement with experimental data in both pure and racemic solubility. In the other hand, determination of molecular parameters of NRTL-SAC equation will help estimation of the solubility of Ketamine in other solvents and enantiomeric compositions.

\section{REFERENCES}

[1] Bruice PY. Organic Chemistry. 6th ed. Pearson International Edition: USA 2011

[2] Fox MA. Whitesell JK. Organic Chemistry. Jones \& Bartlett Publishers: Boston 1994.

[3] Drayer DE. Pharmacodynamic and Pharmacokinetic Differences between Drug Enantiomers in Humans: An Overview. Clin Pharmacol Ther 1986; 40: 125-133. http://dx.doi.org/10.1038/clpt.1986.150

[4] Polenske D, Lorenz H, Seidel-Morgenstern A. The Binary Phase Diagram of Propranolol Hydrochloride and Crystallization-Based Enantioseparation. J Pharm Sci 2010; 99: 1762-1773. http://dx.doi.org/10.1002/jps.21943

[5] Collet A. Separation and Purification of Enantiomers by Crystallization Methods. Enantiomer 1999; 4: 157-172.

[6] Lorenz H, Seidel-Morgenstern A. Binary and Ternary Phase Diagram of Two Enantiomers in Solvent Systems. Thermochimica Acta 2002; 382: 129-142. http://dx.doi.org/10.1016/S0040-6031(01)00746-8 
[7] Wilson GM. Vapor-Liquid Equilibrium. XI. A New Expression for the Excess Free Energy of Mixing. J Am Chem Soc 1964; 86: $127-130$ http://dx.doi.org/10.1021/ja01056a002

[8] Renon H. Prausnitz JM. Local Compositions in Thermodynamic Excess Functions for Liquid Mixtures AIChE 1968; 14: 135-144.

http://dx.doi.org/10.1002/aic.690140124

[9] Abrams DS, Prausnitz JM. Statistical Thermodynamics of Liquid Mixtures: A New Expression for the Excess Gibbs Energy of Partly or Completely Miscible Systems. AIChE 1975; 21: 116-128. http://dx.doi.org/10.1002/aic.690210115

[10] Hansen CM. Hansen Solubility Parameters: A User's Handbook; CRC Press: Boca Raton, FL 2000.

[11] Fredenslund A, Jones RL, Prausnitz JM. Group Contribution Estimation of Activity Coefficient in non Ideal Liquid Mixtures. AIChE J 1975; 21: 1086-1099. http://dx.doi.org/10.1002/aic.690210607

[12] Chen C-C, Song Y. Solubility Modeling with a Non-Random Two- Liquid Segment Activity Coefficient Model. Ind Eng Chem Res 2004; 43: 8354-8362. http://dx.doi.org/10.1021/ie049463u

[13] Mirmehrabi M, Rohani S, Murthy KSK, Radatus B. Solubility, Dissolution Rate and Phase Transition Studies of Ranitidine Hydrochloride Tautomeric Forms. Int J Pharmaceut 2004; 282: 73-85 http://dx.doi.org/10.1016/j.ijpharm.2004.05.031

[14] Mirmehrabi M, Rohani S, Perry L. Thermodynamic Modeling of Activity Coefficient and Prediction of Solubility: Part 2. Semipredictive or Semiempirical Models. J Pharmaceut Sci 2006; 95(4): 798-809. http://dx.doi.org/10.1002/jps.20576

[15] Doman ska U, Pelczarska A, Pobudkowska A. Solubility and pKa Determination of Six Structurally Related Phenothiazines. Int J Pharmaceut 2011; 421: 135-144. http://dx.doi.org/10.1016/j.ijpharm.2011.09.040

[16] Sheikhzadeh M, Rohani S, Taffish M, Murad S. Solubility Analysis of Buspirone Hydrochloride Polymorphs
Measurements and Prediction. Int J Pharmaceut 2007; 338: 55-63.

http://dx.doi.org/10.1016/j.ijpharm.2007.01.022

[17] Manifar T, Rohani S. Measurement and Prediction of Solubility of Four Arylamine Molecules in Benzene, Hexane, and Methanol. J Chem Eng Data 2005; 50: 1794-1800. http://dx.doi.org/10.1021/je0495785

[18] Sheikholeslamzadeh E, Rohani S. Vapour-Liquid and Vapour-Liquid-Liquid Equilibrium Modeling for Binary, Ternary, and Quaternary Systems of Solvents. Fluid Phase Equilibria 2012; 333: 97-105. http://dx.doi.org/10.1016/j.fluid.2012.07.016

[19] Prausnitz JM, Lichtenthaler RN, Azevedo EG. Molecular Thermodynamics of Fluid-Phase Equilibria. 2nd ed. PTR Prentice-Hall, Inc. Englewood Cliffs NJ, USA 1986. http://dx.doi.org/10.1002/cjce.5450780222

[20] Tamagawa RE, Miranda EA, Santana CC, Giulietti M Determination of the Binary and Ternary Phase Diagrams of

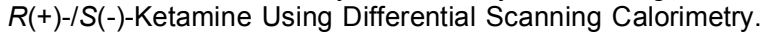
J Chem Eng Data 2009; 54: 16-21. http://dx.doi.org/10.1021/je8002207

[21] Zhang Y, Ray A, Rohani S. Measurement and Prediction of Phase Diagrams of the Enantiomeric 3-Chloromandelic Acid System. Chem Eng Sci 2009 64: 192-197. http://dx.doi.org/10.1016/j.ces.2008.10.010

[22] Lorenze H, Sapoundjiev D, Seidel-Morgenstern A Enantiomeric Mandelic acid system-melting point phase diagram and solubility in water. J Chem Eng Data 2002; 47: 1280. http://dx.doi.org/10.1021/je0200620

[23] Atashpaz-Gargari E, Lucas C. Imperialist Competitive Algorithm: An Algorithm for Optimization Inspired by Imperialistic Competition, Evolutionary Computation. 2007. CEC 2007; IEEE Congress on, 4661-4667. http://dx.doi.org/10.1109/CEC.2007.4425083

[24] Hansen HK, Rasmussen $P$, Fredenslund A, Schiller $M$ Gmehling J. Vapor-Liquid Equilibria by UNIFAC Group Contribution. 5. Revision and Extension. I \& EC Res 1991; 30: 2352-2355. http://dx.doi.org/10.1021/ie00058a017 